\title{
Historia reciente en la escuela colombiana: acercamiento a las nociones de memoria, historia y conflicto
}

Recent History in the Colombian School: Approach to the Concepts of Memory, History and Conflict

História recente na escola colombiana: aproximação aos conceitos de memória, história e conflito

\section{Lorena Torres Gámez * iD orcid.org/0000-0003-4438-2939}

\section{Artículo de investigación}

Revista Colombiana de Educación, N. ${ }^{\circ} 71$. Segundo semestre de 2016, Bogotá, Colombia.

Para citar: Torres, L. (2O16). Historia reciente en la escuela colombiana: acercamiento a las nociones de memoria, historia y conflicto. Revista Colombiana de Educación, (71), 165-185.

Recibido: 06/02/16

Evaluado: 21/03/16

* Licenciada en Ciencias sociales, Universidad Pedagógica Nacional, Colombia. Magister en Historia, Universidad Federal de Mato Grosso, Brasil. Actualmente labora en CINEP Centro de investigación y educación Popular y es Investigadora Programa ciudadanía y paz: Proyecto "Travesia de la Luz". Correo electrónico: Itorresoei@gmail.com itorres@cinep.org.co 


\section{Resumen}

El abordaje de la historia reciente del país en el contexto de diálogos de paz y posible post-acuerdo inquieta a la escuela en lo que respecta a las repercusiones curriculares, las responsabilidades frente a la reparación y las nuevas representaciones de los daños y afectaciones causados por la guerra. El presente artículo expone reflexiones conceptuales en torno a la relación de memoria, historia y conflicto teniendo en cuenta los requerimientos al sector educativo en el marco transicional para la paz; metodológicamente asume la revisión bibliográfica y el aporte reflexivo sobre las nociones mencionadas como contribución a los nuevos modos de comprensión de la enseñanza de la historia y las responsabilidades colectivas de ejercicios de memoria y reconstrucción de la historia reciente en la escuela.

\section{Palabras clave}

memoria, enseñanza de la historia; conflicto; violencia

\section{Keywords}

memory; history teaching; conflict; violence

\begin{abstract}
Addressing the recent history of our country in the context of post-agreement is a concern to the school in terms of its currículum implications and responsibilities versus reparation and new representations of the damages and disruptions caused by war. This paper presents conceptual reflections on the relationship between memory, history and conflict, taking into account the requirements of the education sector in the transitional framework for peace. Methodologically, it assumes the literature review and the thoughtful input on the concepts mentioned as a contribution to new ways of understanding the teaching of history and collective responsibilities on memory practices and reconstruction of recent history in school.
\end{abstract}

\section{Resumo}

A abordagem da história recente do país no contexto do pós-acordo inquieta á escola em relação ás repercussões curriculares, as responsabilidades frente á reparação e as novas representações dos danos e afetações causadas pela guerra. $O$ presente artigo expõe reflexões conceptuais sobre a relação de memória, história e o conflito tendo em conta os requerimentos ao setor educativo no cenário transicional para a paz, metodologicamente assume a revisão bibliográfica e o aporte reflexivo sobre as noções mencionadas como contribuição aos novos modos de compreensão do ensino da história e as responsabilidades coletivas de exercícios de memória e reconstrução da história recente na escola.

\section{Palavras chave}

memória; ensino da história; conflito; violência 
La memoria es el presente del pasado, y no puede constituirse en forma independiente de los dilemas del tiempo desde el cual es elaborada. Apropiarse significativamente del pasado marcado por la experiencia del terrorismo de Estado y del autoritarismo implica asumir el desafío del conflicto por el que hoy está atravesada su memoria. E implica el esfuerzo de apertura para que sean las nuevas generaciones que estamos formando en las escuelas las que se sumen a este proceso con sus propias preguntas y percepciones.

S. Raggio

La enseñanza del pasado reciente Hacer memoria y escribir la Historia en el aula

$\mathrm{L}$

os trabajos historiográficos en Colombia han promovido el análisis del pasado reciente a partir de la recuperación material e inmaterial de versiones históricas de carácter público y privado a nivel regional y nacional, al mismo tiempo que se han convertido en reflejo de ejercicios de memoria correspondientes a temporalidades, espacialidades y narrativas que expresan los límites y posibilidades de la labor historiográfica y de los trabajos de memoria sobre el conflicto armado.

Los espacios educativos formales como la escuela no han sido ajenos al tema ni a la intrincada relación entre historia-memoria. Por el contrario, la representación del pasado y la rememoración de lo ausente han hecho parte de la reafirmación escolar en la construcción de identidad nacional (Carretero, 2007), equipada de memorias con discursos rememorativos, memorialísticos y conmemorativos de modelos ideales, heroicos y bélicos.

En este contexto, este artículo expresa el interés por comprender las implicaciones de la producción y reproducción de las memorias de la historia reciente del conflicto armado colombiano en la escuela, partiendo de que el tratamiento de la memoria en el campo educativo está sujeto a responsabilidades éticas, políticas, jurídicas y académicas que denotan la complejidad del trabajo con versiones diversas sobre acontecimientos traumáticos generados por la guerra. Por tanto, se debe ser cuidadoso en el acercamiento al tema, más aún en tiempos de acuerdos de paz.

La exposición conceptual de algunos postulados sobre las nociones de memoria, historia y escuela se complementa de forma relacional con las nociones de violencia y conflicto, suponiendo su importancia para la comprensión de la historia reciente del país a través de la historia escolar. Además, se presentan algunas ideas generales sobre la significancia de la cultura histórica y los ejercicios de memoria.

\section{Fronteras difusas: historia, historia reciente y memoria}

A principios del siglo xx los postulados en torno a la memoria se reducían a la explicación de esta como proceso de localización de recuerdos; 
como "un esfuerzo creciente de expansión por el cual, siempre presente a sí misma, desplegaba sus recuerdos sobre una superficie cada vez más extensa y terminaba por distinguir así, en un cúmulo hasta allí confuso, el recuerdo que no hallaba su sitio" (Bergson, 1896, citado por Halbwachs, 2011, p. 30).

Con la mímesis narrativa de las últimas décadas del siglo xx la memoria pasó a ser entendida como actividad social compartida por sujetos, que en el marco de procesos de intercambio social generan recuerdos de carácter individual o colectivo reelaborados constantemente y representados a través de diferentes formas de registro y consolidación del pasado. Por ende, la memoria se entiende como manifestación que surge en conflictos, deslocamientos y transferencias de la relación entre presente y pasado, con transformación de la experiencia temporal y la refiguración de la narrativa de esta (Ricoeur, 2000).

La historia del tiempo presente, también denominada historia reciente, historia contemporánea o historia inmediata, fue parte de la revitalización del campo de las ciencias sociales en la década de 1980, así como, las dinámicas culturales que privilegiaron la memoria como connotación sobre la noción de coyuntura y acontecimiento al ser una práctica y representación portadora de subjetividad, temporalidad (Fazio, 2010).

La historia del tiempo presente racionalizada desde el enfoque social y cultural del paradigma narrativista demostró su capacidad de reivindicar el sentido histórico como percepción y diferencia de la conciencia en el tiempo, la interpretación de lo percibido mediante la articulación narrativa y orientación de la vida práctica encadenada a la autorreflexión del pensamiento histórico.

Desde este enfoque, la relación historia-memoria adquirió un lugar protagónico en los ámbitos jurídico, político y cultural de los discursos de verdad, justicia y reparación de eventos traumáticos del siglo xx en Europa, África y Suramérica, lo que Huyssen denomina el discurso global de la memoria, para referirse a la aparición de un interés por el pasado y su compilación en los discursos políticos en un momento en el que los derechos humanos se convirtieron en una fuerza poderosa (2011, p. 184).

De acuerdo con Ricoeur, la memoria se entendió desde la descripción de los fenómenos que la producen y mantienen como único recurso para significar el carácter del pasado, como sistema de representaciones que acoge la figura de testigo en el sujeto que recuerda, entendiendo la representación como generadora y resultado de memoria en el campo social, conforme a "la designación de creencias y normas que confieren una articulación simbólica a la construcción del lazo social y a la formación de identidades" (Ricoeur, 2000, p. 18).

En esta dinámica, la memoria y la historia son representaciones colectivas del pasado tal como se forjan en el presente, y están inscritas en 
una continuidad temporal de identidad, sentido, significación y dirección dentro del ejercicio de representación del pasado (Traverso, 2007).

Memoria e Historia no están separadas por barreras, sino que interactúan en forma permanente, inevitablemente se deriva una relación privilegiada entre las memorias "fuertes" y la escritura de la historia. Cuanto más fuerte es la memoria -en términos de reconocimiento público e institucional-, el pasado del cual esta es un vector se torna más susceptible de ser explorado y transformado en la historia (Traverso, 2007, p. 88).

Las fronteras borrosas entre historia y memoria, y los sentidos heurísticos que las remiten al acercamiento y la recuperación de imágenes sobre el pasado, las enfrenta a lecturas pretenciosas en la definición del lugar de acción de cada una.

Aquí, intentamos acudir a postulados que permitan establecer una relación distinguida por el carácter epistemológico de la historia, al tratarse de una disciplina académica con resultados cognoscitivos, con métodos y reglas de investigación articulados a un campo de legitimación de la racionalidad histórica que requiere una actividad cognitiva (Rüsen, 2010), y la memoria como capacidad humana de rememoración individual y colectiva, ejercida en un marco social que le permite al pasado tornarse presente, constituyendo la experiencia vivida de un grupo para su formación, cohesión social y preservación (Sarlo, 2012).

La naturaleza social de los eventos hace que la memoria tenga en sí misma un enfoque cognitivo que se articula -no siempre de forma acorde- a la expresión y el establecimiento de ejes temporales y narrativos. Eso explica por qué el recuerdo es producto de una selección, un ejercicio determinante que pone a los sujetos de forma consciente o inconsciente en un contexto social en el que se evoca y registra a partir de los intereses del presente, obviando determinados aspectos del pasado y privilegiando otros.

La memoria no es estática; es esencialmente constructiva, en la medida en que los recuerdos son recreaciones del pasado. El recuerdo es una imagen transportada del pasado y adherida a otras imágenes,

es en gran medida, una reconstrucción del pasado que se realiza con la ayuda de datos tomados del presente y es, por lo demás, preparada por otras reconstrucciones hechas en épocas anteriores, en las que la imagen del pasado ha sido ya sumamente alterada (Halbwachs, 2011, p. 118).

El trabajo clásico de Le Goff, aún referenciado como pionero en cuanto al vínculo historia-memoria, entiende la memoria como fenómeno individual y psicológico, "como capacidad de conservar determinadas informaciones, remite ante todo a un complejo de funciones psíquicas, 
con el auxilio de las cuales el hombre está en condiciones de actualizar impresiones o informaciones pasadas, que él se imagina como pasadas" (2003, p. 130).

La memoria se genera en la vida social y varía en función de la presencia o de la ausencia de la escritura, siendo objeto de atención del Estado según el interés de conservar determinados hechos. En cuanto a la historia, es la ciencia del tiempo, ligada a diferentes concepciones de tiempo que existen en una sociedad.

La historia es duración, el pasado es al mismo tiempo pasado y presente. Compete al historiador hacer un estudio "objetivo" del pasado sobre una doble forma. Comprometido en la historia, no atenderá ciertamente la verdadera objetividad, pero ninguna otra historia es posible. El historiador hará procesos en la comprensión de la historia esforzándose para explicar, en su proceso de análisis, tal como un observador científico lo hace, las modificaciones que eventualmente introduce en su proyecto de observación (Le Goff, 2003, p. 51).

En ese intercambio entre memoria e historia, Sarlo afirma que la memoria "coloniza el pasado y lo organiza sobre la base de las concepciones y las emociones del presente" (2005, p. 92); lo desafía y le otorga grados de significatividad al relato, que con una inclinación por el detalle y la precisión descriptiva de los hechos se asegura en una ambición de defensa propia.

Por el contrario, la disciplina histórica se ubica lejos de la utopía de que su narración puede incluirlo todo. Opera con elipsis, por razones metodológicas y expositivas [...]. Lo específico histórico es lo que puede componer la intriga, no como simple detalle verosímil sino como rasgo significativo; no es una expansión descriptiva de la intriga sino un elemento constitutivo sometido a la lógica (Sarlo, 2005, p. 68).

Desde la perspectiva de Sauvage la relación entre memoria e historia del tiempo presente reside en la posibilidad del acceso al reflejo de la experiencia pasada, desde testimonios que anudan el recuerdo a lo vivido y permiten observar el encuentro entre memoria individual y memoria colectiva con una nueva manera de hacer historia.

Por último, la memoria es objeto de la historia en la medida en que la memoria de los actores (los que hacen la historia) es un elemento importante en la evolución de las sociedades. En este sentido, la memoria es un poderoso factor de comportamiento político (Sauvage, 1998, p. 68).

Esta reflexión sobre la relación entre memoria e historia nos permite afirmar que son los intereses del presente los que hacen que los constructores de la historia procedan a seleccionar determinados aspectos 
del pasado y obviar otros. Peter Burke (1993) afirma que la memoria compete a los historiadores al menos en dos maneras: como fuente histórica y como fenómeno histórico, al entender que la historia de la memoria "no se trata solo de estudiar los hechos en sí, sino las razones de su perdurabilidad entre los miembros de un grupo o de una sociedad a través del tiempo" (Aguilar, 2008, p. 49).

Además, "la recuperación del pasado es indispensable; lo cual no significa que el pasado deba regir el presente, sino, al contrario, este hará del pasado el uso que prefiera" (Todorov, 2008, p. 40). Más allá de la idea vaga de querer recordar, esta reflexión nos remite a la lectura del presente en el advenimiento del pasado, en un contexto de riesgo al culto de lo exacerbado, efímero, de ritmo rápido y frágil ante el placer del instante, o a los olvidos públicos como fenómenos de silencio en función de intereses políticos.

De igual forma, parece constructivo el acercamiento entre los dos conceptos, al igual que sus justas diferenciaciones, porque sin querer privilegiar o anteponer la historia frente a cualquier tipo de iniciativa de estudio del pasado, algunas operaciones como división, selección, exclusión, colección y producción de información para reconstrucción del pasado, son propias de la disciplina histórica y sus estrategias narrativas.

\section{Re-significar la historia, re-semantizar la memoria y re-construir el pasado en la escuela}

Memoria, historia y escuela encuentran un marco de comprensión en la necesidad de crear diversos canales de expresión y enseñanza de la historia, apuntando a la memoria como campo de trabajo pedagógico convergente para la formación de sujetos conscientes de las intermediaciones, fracturas y continuidades de la historia como material de aprendizaje y transformación social.

La historia escolar es una prueba contundente del olvido y la selección de acontecimientos con los que públicamente el pasado puede ser tratado. A pesar de eso, también es punto de partida hacia el conocimiento y la reproducción de estrategias de agenciamiento y posicionamiento de los sujetos protagonistas en la construcción social de la memoria, lo que implica abatir la cómoda posición sobre la historia escolar como transmisora de memoria institucional u oficial, caracterizada por la visibilidad que adquiere en el espacio público, reflejada en los monumentos, en las conmemoraciones, e impulsada a través de las políticas de la memoria (Aguilar, 2008, p. 57).

Entendiendo que "la escuela se constituye en el principal escenario de materialización de las 'políticas de la memoria', que son expresión de 
una memoria e historia oficial de sectores dominantes de la sociedad" (Jiménez, Infante y Cortés, 2012, p. 293) o proyectos políticos de olvido que posicionan discursos memorialistas en memorias de unificación nacional; hablar de las memorias en el ámbito escolar, implica debatir esta predeterminación y dirigir la mirada a los espacios, discursos y prácticas que constituyen sus relaciones, deseos y responsabilidades en el plano personal y colectivo frente a la historia del país.

La reconstrucción del pasado y su abordaje en marcos sociales, como la escuela, lo convierten en objeto de estudio en el que se admite un encuentro a diferentes niveles entre memoria, historia e identidad puesto que la problematización de la memoria es un eslabón para el reconocimiento y acercamiento de lo que somos, fuimos y seremos.

La inquietante e intensa necesidad de reconocer un tejido identitario con temporalidades y narrativas colectivas provee elementos para historizar la memoria, y abordar los sentidos del pasado teniendo claro que "el tiempo de las memorias no es lineal, no es cronológico, o racional. Los procesos históricos ligados a memorias de pasados conflictivos tienen momentos de mayor visibilidad y momentos de latencia, de aparente olvido y silencio" (Jelin, 2002, p. 74).

La reflexión en torno a los estadios de comprensión de los contenidos históricos en el escenario escolar y la relación con ejercicios de memoria forman parte del reconocimiento a la construcción de narrativas planeadas, textualizadas y revisadas dentro del currículo escolar, perfilando la historia como factor de orientación cultural y socialización reflexiva de sistemas de pensamiento propios del área para ejercicios narrativos de la experiencia individual y colectiva en el tiempo.

Desde la interpretación de Jörn Rüsen el aprendizaje histórico es una acción constitutiva de todo conocimiento histórico basado en la conciencia histórica, descrita como una operación mental en la que la experiencia del tiempo es un trabajo cognitivo.

Se trata de un proceso de la conciencia en el que las experiencias del tiempo son interpretadas con relación a las intenciones de actuar y, en cuanto interpretadas, se insieren en la determinación del sentido del mundo y en la auto-interpretación del hombre, parámetros de su orientación en el actuar y en el sufrir (Rüsen, 2001, p. 59).

En esta lógica, el proceso de enseñanza-aprendizaje de la historia es un lugar de enunciación y objetivación donde los sujetos dan sentido a una orientación temporal de la propia vida práctica y sus acontecimientos desde sus subjetividades y experiencias de vida.

Este proceso de re-significación, re-semantización y re-construcción de la historia con potencialidad pedagógica tiene como mínimo cuatro sentidos: la comprensión de la historia presente; la subjetividad de los 
receptores para que el cocimiento histórico no sea postrado como un mero conjunto de reminiscencias; la construcción de identidad histórica a través de la comunicación racional-argumentativa en medio de una intersubjetividad discursiva; y la inclusión y sistematización de los componentes políticos de la conciencia y cultura históricas (Rüsen, 2010).

Al considerar la historia escolar como configuración de las narrativas diversas, entre ellas la "historia nacional" reflejada en los contenidos, textos escolares e intensidad curricular, opera una concepción de tiempo histórico, susceptible de ser preconfigurado, configurado y reconfigurado (Ricoeur, 1997). Esta se concibe como un lugar estratégico para la formación de conocimiento histórico construido desde modalidades escritas u orales sobre memorias específicas, no ajenas a los intereses y sentido desde donde emergen.

De acuerdo con esto, las políticas de la memoria son implantas en lugares estratégicos de reproducción discursiva como la escuela, donde la mayoría de las veces se remiten los mandatos jurídicos con epígrafe de Deber de la memoria, sin previsión a transformaciones notorias en el sentido del acto educacional, para el caso de Colombia encontramos en la política transicional (Ley de Víctimas y Restitución de Tierras 1448 de 2011) - responsabilidades concretas asignadas al sector educativo, algunas presentadas en la siguiente tabla.

Tabla 1. Responsabilidades del sector educativo en el marco para la paz

\begin{tabular}{|c|c|c|}
\hline Norma & Texto jurídico & $\begin{array}{l}\text { Observaciones/Público } \\
\text { objeto }\end{array}$ \\
\hline $\begin{array}{l}\text { Art. } 145 . \\
\text { Acciones } \\
\text { en materia } \\
\text { de memoria } \\
\text { histórica } \\
\text { (Ley } 1448 \\
\text { de 2011) }\end{array}$ & $\begin{array}{l}\text { El Ministerio de Educación Nacional, con } \\
\text { el fin de garantizar una educación de } \\
\text { calidad y pertinente para toda la pobla- } \\
\text { ción, en especial para poblaciones en } \\
\text { condición de vulnerabilidad y afectadas } \\
\text { por la violencia, fomentará desde un en- } \\
\text { foque de derechos, diferencial, territorial } \\
\text { y restitutivo, el desarrollo de programas } \\
\text { y proyectos que promuevan la restitu- } \\
\text { ción y el ejercicio pleno de los derechos, } \\
\text { desarrollen competencias ciudadanas y } \\
\text { científico-sociales en los niños, niñas y } \\
\text { adolescentes del país; y propendan a la } \\
\text { reconciliación y la garantía de no repe- } \\
\text { tición de hechos que atenten contra su } \\
\text { integridad o violen sus derechos. }\end{array}$ & $\begin{array}{l}\text { Acciones mediante las cuales } \\
\text { el Estado promueve la repa- } \\
\text { ración con el reconocimiento } \\
\text { de la institucionalidad y la } \\
\text { sociedad civil en las tareas de } \\
\text { reparación. }\end{array}$ \\
\hline
\end{tabular}

Continúa 


\begin{tabular}{|c|c|c|}
\hline Norma & Texto jurídico & $\begin{array}{l}\text { Observaciones/Público } \\
\text { objeto }\end{array}$ \\
\hline $\begin{array}{l}\text { Art. } 149 . \\
\text { Garantías de } \\
\text { no repetición. } \\
\text { (Ley } 1448 \\
\text { de } 2011 \text { ) }\end{array}$ & $\begin{array}{l}\text { La creación de una pedagogía social que } \\
\text { promueva los valores constitucionales } \\
\text { que fundan la reconciliación, en relación } \\
\text { con los hechos acaecidos en la verdad } \\
\text { histórica. } \\
\text { Diseño de una estrategia única de capaci- } \\
\text { tación y pedagogía en materia de respeto } \\
\text { de los Derechos Humanos y del Derecho } \\
\text { Internacional Humanitario, que incluya } \\
\text { un enfoque diferencial, dirigido a los fun- } \\
\text { cionarios públicos encargados de hacer } \\
\text { cumplir la ley, así como a los miembros } \\
\text { de la Fuerza Pública. La estrategia incluirá } \\
\text { una política de tolerancia cero a la violen- } \\
\text { cia sexual en las entidades del Estado; }\end{array}$ & $\begin{array}{l}\text { Acciones de fortalecimiento } \\
\text { para la reparación efectiva de } \\
\text { la población víctima. }\end{array}$ \\
\hline $\begin{array}{l}\text { Art. } 160 \text { De la } \\
\text { conformación } \\
\text { del Sistema } \\
\text { Nacional de } \\
\text { Atención y } \\
\text { Reparación a las } \\
\text { Víctimas }\end{array}$ & $\begin{array}{l}\text { El Sistema Nacional de Atención y Repa- } \\
\text { ración a las Víctimas estará conformado } \\
\text { por las siguientes entidades y programas: } \\
\text { El Ministerio de la Protección Social, El Mi- } \\
\text { nisterio de Comercio, Industria y Turismo, } \\
\text { El Ministerio de Defensa Nacional [...]. El } \\
\text { Ministerio de Educación Nacional. }\end{array}$ & $\begin{array}{l}\text { Cuerpo institucional para el } \\
\text { desarrollo de la propuesta } \\
\text { jurídica transicional con el Mi- } \\
\text { nisterio de Educción Nacional } \\
\text { entre mucho otros. }\end{array}$ \\
\hline $\begin{array}{l}\text { Art. } 189 . \\
\text { Componentes } \\
\text { del Programa } \\
\text { de Derechos } \\
\text { Humanos } \\
\text { y Memoria } \\
\text { Histórica }\end{array}$ & $\begin{array}{l}\text { Componente 2: } \\
\text { Actividades de pedagogía. Este compo- } \\
\text { nente se desarrollará en concordancia } \\
\text { con el Plan Nacional de Educación en } \\
\text { Derechos Humanos, conjuntamente con } \\
\text { los ministerios de Educación Nacional y } \\
\text { Cultura, con el Programa Presidencial para } \\
\text { la Protección y Vigilancia de los Derechos } \\
\text { Humanos y Derecho Internacional Huma- } \\
\text { nitario y el Departamento Administrativo } \\
\text { de la Ciencia, Tecnología e Innovación, } \\
\text { Alta Consejería para la Equidad de la } \\
\text { Mujer, entre otras entidades, para crear y } \\
\text { cimentar una cultura de conocimiento y } \\
\text { comprensión de la historia política y so- } \\
\text { cial de Colombia en el marco del conflicto } \\
\text { armado interno. }\end{array}$ & $\begin{array}{l}\text { La construcción de la propues- } \\
\text { ta pedagógica debe partir del } \\
\text { reconocimiento de experien- } \\
\text { cias de diferentes instituciones } \\
\text { que han trabajado el tema. }\end{array}$ \\
\hline $\begin{array}{l}\text { Art. } 210 \text {. De la } \\
\text { pedagogía para } \\
\text { la reconciliación } \\
\text { y construcción } \\
\text { de paz. } \\
\text { (Ley } 1448 \\
\text { de } 2011 \text { ) }\end{array}$ & $\begin{array}{l}\text { La Unidad Administrativa Especial } \\
\text { para la Atención y Reparación Integral } \\
\text { a Víctimas, en un término de ocho (8) } \\
\text { meses contados a partir de la publicación } \\
\text { del presente Decreto, en coordinación } \\
\text { con el Ministerio de Educación Nacional } \\
\text { y el Instituto Colombiano de Bienestar } \\
\text { Familiar, diseñará e implementará una } \\
\text { pedagogía social para la reconciliación } \\
\text { que sea replicada en el territorio nacional. }\end{array}$ & $\begin{array}{l}\text { La Ley propone la construc- } \\
\text { ción de la pedagogía social } \\
\text { para la sociedad civil de forma } \\
\text { generalizada, muchas veces, } \\
\text { sin partir del reconocimiento } \\
\text { territorial de las diferentes } \\
\text { poblaciones afectadas. }\end{array}$ \\
\hline
\end{tabular}




\begin{tabular}{|l|l|l|}
\hline \multicolumn{1}{|c|}{ Norma } & \multicolumn{1}{|c|}{ Texto jurídico } & \multicolumn{1}{c|}{$\begin{array}{c}\text { Observaciones/Público } \\
\text { objeto }\end{array}$} \\
\hline $\begin{array}{l}\text { Art. 117. } \\
\text { Prioridad en } \\
\text { los beneficios } \\
\text { consagrados } \\
\text { en la Ley } 731 \\
\text { de 2002 }\end{array}$ & $\begin{array}{l}\text { Las mujeres a quienes se les restituya } \\
\text { o formalice predios en los términos de } \\
\text { la presente ley tendrán prioridad en la } \\
\text { aplicación de los beneficios a que se } \\
\text { refiere la ley 73l de 2002, en materia de } \\
\text { crédito, adjudicación de tierras, garantías, } \\
\text { seguridad social, educación, capacitación } \\
\text { y recreación, subsidio familiar, planes y } \\
\text { programas de reforestación, y jornadas de } \\
\text { cedulación. }\end{array}$ & $\begin{array}{l}\text { Mujeres víctimas a quienes se } \\
\text { les debe favorecer con espe- } \\
\text { cial protección del Estado, para } \\
\text { garantizar el debido proceso } \\
\text { de reparación contemplado } \\
\text { en la Ley. }\end{array}$ \\
\hline $\begin{array}{l}\text { Ley 1732 de 2014 } \\
\text { Decreto 1038 de } \\
2015, \text { Cátedra de } \\
\text { la paz }\end{array}$ & $\begin{array}{l}\text { Reglamentación que establece la obligato- } \\
\text { riedad de la Cátedra de la Paz en todas las } \\
\text { instituciones educativas del país y señala } \\
\text { a un pénsum académico flexible, el cual } \\
\text { será el punto de partida para que cada } \\
\text { institución educativa lo adecue de acuerdo } \\
\text { a características temporales y espaciales } \\
\text { concretas. }\end{array}$ & $\begin{array}{l}\text { Política nacional para la imple- } \\
\text { mentación y el desarrollo de } \\
\text { la Cátedra de la Paz en todos } \\
\text { los niveles escolares, dejando } \\
\text { grados de autonomía a las insti- } \\
\text { tuciones en su cumplimiento. } \\
\text { Vale la pena indagar sobre cuál } \\
\text { va a ser la forma de desarrollo } \\
\text { de esta cátedra, además de las } \\
\text { herramientas que ofrecerá el } \\
\text { Estado para tal trabajo. }\end{array}$ \\
\hline
\end{tabular}

Fuente: Ley de Víctimas y Restitución de Tierras 1448 de 2011, artículos relacionados con las responsabilidades del sector educativo en términos de reparación a población víctima.

Esta información presenta algunos de los requerimientos específicos realizados al sector educativo. Por ejemplo, en el artículo 145, dedicado a las acciones en materia de memoria histórica, se mencionan de forma detallada siete acciones que deberán ser desarrolladas por el sector público o el privado, propendiendo el tratamiento de la memoria mediante el desarrollo de Programas y Proyectos para ejercicios de memoria histórica y derechos humanos.

De nuevo aparece la dicotomía entre historia y memoria en la escuela, suscitándonos interrogantes como: ¿Cuáles son las nociones de presente que circulan en momentos de transición? ¿Cómo se presenta el pasado reciente de nuestro país en el escenario escolar? ¿Qué perspectivas existen sobre la paz en Colombia? ¿Cuáles son los referentes espaciales, temporales y narrativos para el tratamiento de la historia reciente de nuestro país? ¿Cómo la memoria da cuenta de ejercicios de hegemonización de versiones históricas en la escuela? ¿Cuáles son las cronologías de la escuela para referirse al conflicto armado? Estos cuestionamientos evidencian la inevitable relación entre los discursos de la historia escolar, la política educativa y la política de la memoria.

Se trata de una clave compuesta por tres elementos (escuela, memoria y enseñanza de la historia reciente) con carácter polémico, por su convivencia con el pasado presente, con la supervivencia de los actores y 
protagonistas de los hechos, personas en condiciones testimoniales en el marco de la existencia de una memoria social contemporánea en continua construcción por los sujetos de su tiempo, siendo su principal dificultad la falta de cierre con versiones diversas que la ubica en planos relativos.

El estudio del pasado reciente ha enfrentado críticas conforme la delimitación temporal, la falta de fronteras cronológicas precisas, "los debates de qué acontecimientos y fechas enmarcan la historia reciente carecen de sentido en tanto y en cuanto esta constituye un campo en constante movimiento con periodizaciones más o menos elásticas y variables" (Franco y Levín, 2007, p. 33).

Conforme esto, podemos decir que la atención estructural en la que se solventa la propuesta de paz en Colombia posiciona la escuela como lugar protagónico, no solo en la heredada tarea de reproducción y transmisión de verdades históricas, sino en la promoción consciente de políticas de la memoria, y con ello, los cuestionamientos históricos, holísticos y sistemáticos que hacen de la práctica pedagógica una propuesta de tratamiento y acercamiento a los pasados recientes.

Sin embargo, esta tarea se dificulta con la brecha entre la formulación de políticas educativas y los requerimientos del marco jurídico para la paz. Los estándares nacionales e internacionales de educación continúan ponderando las nociones de educación de calidad para la competencia, por encima de las condiciones reales de la escuela y sus procesos de re-significación, re-semantización y re-construcción de los pasados recientes.

La política educativa y la política de la memoria en Colombia transitan por caminos incongruentes en cuanto a lo que proponen y las condiciones materiales para Ilevarlo a cabo, en coherencia política estos dos componentes deberían ser elementos garantes para el acercamiento al tema de los derechos humanos, como condición necesaria en la formación de sujetos para la paz, entendedores del poder y empoderamiento desde maneras diferentes a la violencia, y no como enunciados aislados a su realidad.

Las elaboraciones de los pasados traumáticos necesitan de contextos coherentes con voluntad política, por eso, resulta urgente producir consensos asociados a valores democráticos, en donde el diálogo no gire tan solo en torno a las experiencias límite, y las condiciones que las hicieron posibles (Raggio, 2004, p. 4). Sino también en la demanda y exigibilidad de derechos como condición necesaria para la reparación de la sociedad en general.

\section{Aportes conceptuales para el tratamiento del con- flicto armado en la escuela}

En Colombia se ha optado por asumir la existencia de un conflicto armado interno, "propiciado y acentuado en gran medida por dos factores 
sustanciales: por un lado, las grandes brechas de injusticia e inequidad social, y por el otro, la desatención a los clamores de las víctimas de los actores armados" (Ministerio de Justicia, 2011, p. 9).

En el marco del derecho y deber social para la paz se reconoce públicamente la existencia de un conflicto armado interno como primera tarea de la sociedad para la construcción de condiciones y garantías en procesos de justicia, reparación y no repetición. Hablar de conflicto como construcción histórica converge en el análisis de la guerra como un sistema de durabilidad, sostenibilidad, legitimidad y escala para caracterización y definición de los actores armados, sus mecanismos, perspectivas de supervivencia, de ampliación y de victoria o derrota político-militar (Lepri, 2006, p. 34).

Desde esta perspectiva el manejo conceptual de los términos de violencia y conflicto es pertinente para el abordaje de la historia reciente de Colombia, como fenómeno multicausal, con fronteras interpretativas flexibles y generadoras de ambientes de inseguridad (Camelo, 2015), además, el acercamiento conceptual es puente para el esclarecimiento histórico y la comprensión del poder comunicativo de los enunciados narrativos que re-significan la historia como una producción de intereses, tensiones y poderes.

El abordaje conceptual permite nuevas lecturas de la reconstrucción de eventos significantes, y re-semantizados desde los lugares donde se nombran los sujetos. A continuación, proponemos un acercamiento a las nociones de violencia y conflicto como ejes denotativos de la realidad colombiana.

En un plano general, la explicación del conflicto está asociada a procesos en los que se manifiestan puntos contrapuestos entre individuos que hacen uso de la violencia en medio de la existencia de grados de tensión, poder y dominación. Aun así, cabe distinguir desde un inicio que

conflicto armado no es sinónimo de violencia que, obviamente, es uno de sus medios; el conflicto está inserto en sociedades con historias y memorias, considerado en un mediano plazo, digamos que Colombia a partir de la mitad de la década de 1940 (Palacios, 2012, p. 26).

El término violencia se ha estudiado técnicamente con relación a su presencia en el comportamiento y las manifestaciones del ser humano. El terreno acotado al estudio de la violencia lo realizaron la escuela francesa y alemana después de la Segunda Guerra Mundial, con una variedad semántica de extralimitación en la especificidad del uso del término, pues etimológicamente la palabra violencia significa hacer uso de la fuerza en contra de algo. La diversificación en su uso ha dificultado la definición del término en forma suficientemente estricta y delimitada. 
El concepto de violencia, en su sentido tradicional de empleo de la fuerza para causar daño, se ha visto siempre como una justificación del empleo de la fuerza coercitiva a modo de respuesta. Así pues, a medida que se va ampliando el significado del término "violencia", ocurre lo mismo con la gama de comportamientos que pueden alegarse para justificar una respuesta violenta (Platt, 1992,p.68).

Una buena parte de los acercamientos a la teoría de la violencia establece una relación cercana con la política. La mayoría de reflexiones en torno a este vínculo acogen la conceptualización teórica bajo la identificación de la violencia como problema del Estado, con dos posiciones diferentes. Por un lado, la violencia en cuanto mecanismo ilegal e ilegitimo de la fuerza; por otro, la legitimidad de la fuerza en la designación de la potestad y el monopolio sobre el uso de la violencia y el poder concedido al Estado.

El problema no consiste en asociar la noción de violencia al contexto social o político del ser humano y sus relaciones de competitividad, pues tal como lo expone el propio Hobbes

La competencia por tener más riquezas, más honores, más súbditos o cualquier otro tipo de poder lleva a la confrontación, la enemistad y la guerra, porque la forma en que cada uno de los que participan en la competencia puede satisfacer su deseo de matar, dominar, reemplazar o rechazar al otro (2007, p. 161).

Por el contrario, la visión de confrontación y competitividad debe ponerse primordialmente en los planos político, social y económico, para entender estructuralmente la violencia política, sus intereses y estrategias de control.

Buscando denominadores comunes ofrecidos por diferentes autores sobre la "violencia", acudimos a sus características principales, procurando presentar la síntesis de un conjunto de cualidades del término como fenómeno social y político. Para Alain Pessin

La violencia está siempre presente en la vida social. Haciéndose eco de ese llamado al relativismo histórico, sostiene que la violencia ha existido siempre. Es, más bien, que ciertos períodos históricos no hacen más que reactualizar la violencia. Sabemos, dice, que la violencia no se recuerda sino cuando se desborda y que no tenemos conciencia de ella hasta que se vuelve problema; es cuando la violencia está mal negociada, mal tomada a cargo dentro del ejercicio corriente de la vida social, que ella se sedimenta y puede aparecer bajo una forma súbita y, particularmente, brutal (2009, p. 32).

Atendiendo a esta perspectiva, existen elementos semejantes con Alain Michaud (1973), quien desde una mirada antropológica supone 
que el concepto de violencia ha servido para entender el caos de los fenómenos políticos cuando las reglas sociales son desatendidas, haciendo de la violencia un conjunto de comportamientos y expectativas de tradición histórica.

Este concepto como componente social de trayectoria individual y colectiva bajo una visión hobbesiana de estado natural, se concibe con la presencia de la violencia ante la ausencia de cualquier norma intersubjetiva que evite el deseo insaciable de poder y egoísmo, como una constante institucional, siempre presente en la vida social (Girard, 1983).

Según estos postulados y situándonos en las especificidades de Colombia, nos preguntamos por las violencias ejercidas en el país después de la segunda mitad del siglo xx: ¿será que el desacato del equilibrio entre poder y dominación ha llevado a la manutención de discursos de homogeneidad y naturalización de una visión prosaica de la violencia?

Para Daniel Pecaut el fenómeno de la violencia en Colombia está directamente asociado a las transformaciones evidenciadas en "la ausencia o precariedad del Estado, la existencia de una población importante por fuera de la institucionalidad oficial; y la compleja relación que se presenta en Colombia entre periferias y centro" $(2003$, p. 80) además de una "correlación casi inversa entre desarrollo económico y el grado relativo de la violencia" (1997, p. 898).

La manutención de discursos homogeneizantes acerca de las explicaciones del conflicto armado viabiliza la ausencia del Estado y dificulta la mirada sistémica de la guerra a partir de tres condiciones claves e interrelacionadas: la precariedad o el fracaso de los dispositivos institucionales adecuados para el tratamiento de conflictos; las perspectivas de éxito de las partes, representadas en una "economía política positiva" en la que la guerra es mejor opción que la paz; y la cómoda moderación de fuerzas económicas entre los contendores, lo que Nazid Richani denomina cómodo impasse (2003).

\section{Conflicto armado interno}

El conflicto armado aquí no deja de ser una determinación lingüística correspondiente a una simbiosis entre intereses políticos, económicos y mediáticos con efectos profundos de distorsión en el lenguaje y los lugares de experiencia desde donde los grupos sociales han asumido la guerra. En gran parte, el acervo lingüístico que da validez a nominaciones como: guerra civil, guerra contra la sociedad, conflicto armado o guerra narcoterrorista etc., pertenece a dinámicas de exportación, recepción y adaptación de nociones globales de seguridad y orden. 
El concepto de conflicto armado interno hace referencia al prolongado período de violencia mantenido en el país desde la década de 1960, el cual empezó a ser usado en presencia del fenómeno político-militar de la Guerra Fría, cuando la violencia escalaba a un ritmo veloz calibrado por los motores del narcotráfico en gran parte del territorio nacional. Posteriormente, el concepto fue utilizado como marco temporal y propuesta académica en temas de procesos de paz y de justicia transicional.

Los esfuerzos por promover públicamente trabajos de memoria en Colombia están relacionados con la idea de la superación el conflicto armado interno, en un contexto donde el diálogo es una salida a la guerra, y el periodo de transición es una invitación latente a la indagación del pasado-presente y sus memorias oficiales, subterráneas, subalternas y emergentes; con el objetivo de construir escenarios de paz, participación y dignificación desde la comprensión de qué pasó, por qué pasó y quiénes fueron.

La Comisión Histórica del Conflicto y sus Víctimas (CHCV) instalada en La Habana Cuba el 21 de agosto de 2014, tiene como principal objetivo "contribuir a la comprensión de la complejidad del contexto histórico del conflicto armado interno y para proveer insumos para las delegaciones en la discusión en los diferentes puntos del Acuerdo General que están pendientes" especialmente el de las víctimas (Comisión Histórica del Conflicto y sus Víctimas, 2015, p. 8).

El reconocimiento del carácter político del conflicto armado en el marco de la transición hacia la paz posiciona el tema en escenarios públicos donde es posible cuestionar los presentes perpetuos e inamovibles, y donde el reconocimiento de la multicausalidad no lo reduce al problema del narcotráfico, sino que contempla el tratamiento y compromiso estructural garante de procesos de paz y dignificación de la sociedad civil.

En esta medida, confrontar definiciones relativas al significado de la guerra implica reconocer un campo discursivo ceñido a la institucionalización de una cultura política, es decir, del conjunto de "prácticas y representaciones en torno al orden social establecido, a las relaciones de poder, a las modalidades de participación de los sujetos y grupos sociales, a las jerarquías que se establecen entre ellos" (Herrera, Pinilla, Infante y Díaz, 2005, p. 34).

La denominación de conflicto armado interno fue reconocida con estatus político durante el gobierno del presidente Belisario Betancur (19821986), quien dictaminó demasiado tarde el carácter político del conflicto, ante la presencia de un cuerpo de fuerzas paraestatales, reflejado en

la apropiación privada del Estado, que ha dado origen a una clase política que se ha vuelto experta en el manejo burocrático y administrativo del mismo y en la conformación de clientelas políticas que facilitan 
este tipo de apropiación del aparato estatal (Herrera Pinilla e Infante, 2001, p. 42).

Para Henry Pratt el conflicto significa:

Un proceso - situación en el que dos o más seres o grupos humanos tratan activamente de frustrar sus respectivos propósitos, de impedir la satisfacción de sus intereses recíprocos, llegando a lesionar o a destrozar al adversario. Puede ser organizado o no, transitorio o permanente, físico, intelectual o espiritual (2001, p. 75).

El aporte de Pratt a esta discusión se encuentra en la definición de conflicto social como componente del campo global de la categoría de conflicto. El carácter social conduce a pensar una situación en la que confluye una pluralidad de actores con conciencia de incompatibilidad, donde el objetivo es causar daño a uno o más individuos del grupo opuesto a través de la captación de la propiedad, valores culturales y sistema organizacional.

En esta misma línea, Peter Wallensteen (1988) habla del conflicto como una situación social donde mínimo dos partes buscan adquirir el mismo conjunto de recursos escasos. "El conflicto social se refiere precisamente a las desavenencias o problemas de objetivos respecto a los recursos. Se produce entre Estados, grupos o sectores organizados dentro de la sociedad" (Comisión Andina de Juristas, 2014).

Vicenç Fisas ha dedicado gran parte de su obra a entender los conflictos y la promoción de la cultura y la paz. Afirma que el conflicto es un "proceso interactivo" (1987, p. 48) generado en un contexto determinado, es una construcción social, una creación humana, es una condición inherente al ser social-humano diferente a la violencia (puede haber conflictos sin violencia). El ser inherente no lo deja al margen de posibilidades de cambio, con contradicciones de objetivos y conciencias acarreadas por el conflicto, que lo convierte en un fenómeno dinámico.

Según lo anterior, conflicto y violencia son dos nociones que se acogen a una determinación de fenómenos sociales presentes en la historia de Colombia, con causas estructurales, como la notable ausencia del Estado, la imprevisión de proyecto nacional por parte de una elite bipartidista, la prolongada tradición de propiedad de la tierra en pocas manos, el auge y la manutención del narcotráfico a diferentes niveles sociales y la crisis humanitaria en sentido de persecución y violencia política.

Los efectos e impactos más notorios del conflicto armado, sin duda, se reflejan en la multiplicidad de formas de victimización que demarcan el periodo reciente de la historia del país. En esta medida, acercar estas nociones al escenario escolar, específicamente a la enseñanza de la historia, tiene el riesgo de provocar rupturas con las explicaciones lineales sobre el mismo, mantenidas en los contenidos y versiones de los textos escolares.

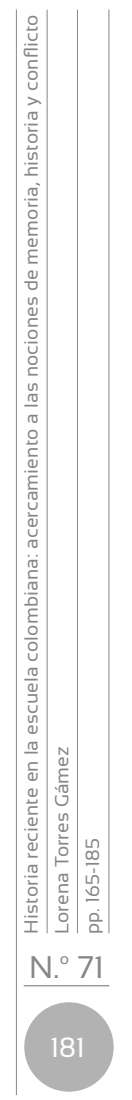


Las consecuencias de otro tratamiento de los relatos históricos del pasado reciente, y la propuesta de una lectura multiperspectiva de estas dos nociones, pueden reflejarse en la formación de sujetos que encuentren un significado en las continuidades y cambios de la historia de su localidad, región y país, al igual que las relaciones empáticas de la experiencia personal (Seixas y Peck, 2004) que permitan el reconocimiento del otro desde su lugar de enunciación.

\section{Consideraciones finales}

El esquema de análisis con el cual proponemos abordar el conflicto armado colombiano en la enseñanza de la historia reciente está planteado desde una perspectiva que converge en la expresión y relación de elementos que han dado vida y durabilidad a la guerra de forma multirrelacionada, en respuesta a ejercicios de poder expresados primordialmente por las élites políticas y económicas del país.

Esta comprensión está circunscrita a una matriz simbólica de construcción de sociedad en la que la definición de lo político pone la violencia más allá de la lectura banalizada de transacciones entre actores armados y Estado, y la sitúa en la pertinencia de integrar los acontecimientos en una trama con sentido, en la que se reconozca el lugar de la memoria colectiva, lo público y lo político en consideración al lugar que ocupa el poder en la unidad de la sociedad y la conformación de identidades sociales (Pécaut, 2003).

El análisis de la historia reciente del país y los ejercicios de memoria en la escuela deben situarse en un enfoque integral y contextualizado que reconozca la presencia de las víctimas en los procesos pedagógicos. Esta concepción va de la mano de cambios en cuanto a la resignificación del concepto de poder como oportunidad para construir acuerdos, transformar realidades y reconstruir tejidos sociales irrumpidos por la guerra.

Para el caso de Colombia, como muchos otros países con conflictos contemporáneos, el trabajo escolar con temas sensibles de violencia política representa un reto ante la mínima distancia temporal con el acontecimeinto, se pueden producir estudios cooptados por el presentismo mesiánico de la verdad inmediata. Entonces, es indispensable ubicar la discusión sobre memorias y su relación con la historia en el ámbito del tiempo presente, y la contemplación de las múltiples respuestas al ultimátum del acontecimiento como escenario inmediato del futuro contemporáneo.

El marco jurídico para la paz en Colombia como eje motivador para pensar los ejercicios de memoria en la escuela evidencia que el tránsito entre pasados-presentes y presentes-pasados se torna una actividad con sentido político, que inevitablemente conduce a reflexionar el conflicto 
armado como resultado de la yuxtaposición de factores que deben ser atendidos estructuralmente junto con la revisión de las demandas sociales, económicas, políticas, culturales y ambientales para una sociedad más justa y equitativa.

Sin embargo, también es pertinente abrir los espacios de discusión en cuanto a la relación entre el marco para la paz, las políticas de la memoria y la política educativa, específicamente en lo que refiere a la comprensión de la historia política y social del país, y su lugar en los mecanismos, pautas y contenidos de las memorias que circularán en la escuela sobre el conflicto.

Al preguntarnos cómo se relaciona la política educativa con las políticas de la memoria del país, entendemos que la transición es un escenario en construcción no exento de tensiones y discusiones, donde la presencia de los maestros es importante, pues, al fin y al cabo, son ellos los sujetos pedagógicos los que materializan en el día a día los proyectos institucionales como la Ley de Víctimas y Restitución de Tierras y la Cátedra para la Paz en condiciones diversas.

Finalmente, las ideas aquí presentadas forman parte de un esfuerzo por construir un sentido de la historia reciente del país con carácter pedagógico en el escenario escolar, motivado por la convicción de que los conocimientos disciplinares no empoderan por sí solos a los sujetos, no reparan, ni reconstruyen tejidos en un país con una larga trayectoria de violencia acentuada en las diferentes esferas de la sociedad. Por el contrario, esto se logra en compañía de propuestas conscientes de formación de sujetos con habilidades cognitivas, reflexivas y afectivas para el reconocimiento de la historia de su país desde miradas críticas, imaginativas, participativas y responsables. 


\section{Referencias bibliográficas}

Aguilar, P. (2008). Politicas de la memoria y memorias de la politica. Madrid: Alianza.

Burke, P. (1993). La historia como memoria colectiva. En Formas de Historia cultural. Madrid: Alianza Universidad.

Camelo, H. (2015). Aportes para la comprensión de la violencia en periodos de post-conflicto. Ciudad Paz-ando, 8, 8-21.

Carretero, M. (2007). Documentos de identidad La construcción de la memoria histórica en un mundo global. Buenos Aires: Paidós.

Comisión Histórica del Conflicto y sus Víctimas (Ed). (2015). Contribución al entendimiento del conflicto armado en Colombia. Bogotá, Colombia. Recuperado de: https://www.mesadeconversaciones.com. co/sites/default/files/Informe\%20Comisi_n\%20Hist_rica\%20del\%20 Conflicto\%20y\%20sus\%20V_ctimas.\%20La\%20Habana,\%20Febrero\%20de\%202015.pdf

Fisas, V. (1987). Introducción al estudio de la Paz y de los conflictos. Barcelona: Lerna.

Franco, M y, Levin, F. (Org). (2007). Historia reciente, perspectivas y desafíos para un campo en construcción. Buenos Aires: Paidós.

Girard, R. (1983). La violencia y lo sagrado. Barcelona: Anagrama.

Halbwachs, M. (2011). La memoria colectiva. Buenos Aires: Miño y Dávila.

Le Goff, J. (2003). Historia e memória (5. ${ }^{a}$ ed.). Campinas, SP: Unicamp.

Herrera, M.; Pinilla, A. e Infante, R. (2001). Conflicto educativo en Colombia y cultura política en Colombia. Nómadas, 15, 40-49.

Herrera, M.; Pinilla, A.; Infante, R. y Díaz, C. (2005). La construcción de cultura política en Colombia. Proyectos hegemónicos y resistencias culturales. Bogotá: Universidad Pedagógica Nacional.

Hobbes, T. (2007). Leviatán, o la materia, forma y poder de una república eclesiástica y civil (2. a ed.). Buenos Aires: Fondo de Cultura Económica.

Huyssen, A. (2011). Modernismo después de la posmodernidad. Barcelona: Gedisa.

Instituto de Estudios Políticos y Relaciones Internacionales (lepri). (2006). Nuestra guerra sin nombre transformaciones del conflicto en Colombia. Bogotá: Norma.

Jelin, E. (2002). Los trabajos de la memoria. Madrid: siglo xxı de España Editores.

Jiménez, A.; Infante, R. y Cortés, R. (2012). Escuela, memoria y conflicto en Colombia. Un ejercicio del Estado del arte de la temática. Revista Colombiana de Educación, 62, 287- 314.

Michaud, A. (1973). La violence. París: Presses Universitaires de France. 
Ley de Víctimas y Restitución de Tierras 1448. Ministerio de Justicia y del Derecho, Bogotá, 2011.

Palacios, M. (2012). Violencia pública en Colombia 1958-2010. Bogotá: Fondo de Cultura Económica.

Pessin, A. (2009). Violence et transgression. En E. Blarir, Aproximación teórica al concepto de violencia: avatares de una definición. Política y cultura. París: Anthropos.

Pécaut, D. (2003). Violencia y política en Colombia: elementos de reflexión. Medellín: Hombre Nuevo.

Platt, T. (1992). Pensar la violencia. Revista Internacional de Ciencias Sociales, 132, 173-179.

Pratt, H. (2001). Diccionario de sociología. Madrid: Fondo de Cultura Económica de España.

Ricoeur, P. (1997). Tempo e narrativa (Vol.3), Campinas: Papirus.

Ricoeur, P. (2000). Historia y memoria. La escritura de la historia y representación del pasado. Annales: Historia y Ciencias Sociales, 55-4, 731-747.

Raggio, S. (2004). La enseñanza del pasado reciente. Hacer memoria y escribir la Historia en el aula. Revista Clio y Asociados, 5, 1-16.

Rüsen, J. (2001). Razão histórica: Teoria da história, fundamentos da ciência histórica. Brasília: Editora Universidade de Brasília.

Rüsen, J. (2010). Aprendizado Histórico. En M. Schmidt, I. Barca y E. Rezende. (Org.) Jörn Rüsen e o ensino de História. Curitiba: UfPr.

Sarlo, B. (2012). Tiempo pasado. Cultura de la memoria y giro subjetivo una discusión. Buenos Aires: Siglo xxı.

Sauvage, P. (1998). Una historia del tiempo presente. Historia Crítica, 17, 59-70.

Seixas, P. y Peck, C. (2004). Teaching historical thinking. En A. Sears e I. Wright (eds.), Challenges and Prospects for Canadian social studies (pp. 109-117). Vancouver: Pacific Educational Press.

Todorov, T. (2008). Los abusos de la memoria (2. ${ }^{a}$ ed.). Barcelona: Paidós Iberoamérica.

Traverso, E. (2007). Historia y memoria: Notas sobre un debate. En M., Franco y F. Levín. Historia reciente, perspectivas y desafíos para un campo en construcción. Buenos Aires: Paidós.

Wallensteen, P. (1988). Peace Research: Achievements and Challenges. Boulder/Londres: Westview. 